\title{
RELATO DE EXPERIÊNCIA NO CONTROLE DE TEMPERATURA DURANTE O PROCESSO DE PASTEURIZAÇÃO NO BANCO DE LEITE MATERNO DE LONDRINA- PR
}

\author{
Márcia Maria Benevenuto de Oliveira* \\ Marli T. Oliveira Vannuchi** \\ Diva Mercedes Imperatriz** \\ Maria Lucilia Monti Magalhães**
}

\begin{abstract}
RESUMO - A curva de pasteurização tem a finalidade de estipular as condições em que o leite materno deverá ser submetido para que seja considerado pasteurizado. Um problema encontrado na confecção da curva em Londrina - PR, é a oscilação de temperatura. Portanto, este trabalho apresenta um método que possibilita o controle de temperatura desde o degelo do leite até o término da pasteurização.
\end{abstract}

\begin{abstract}
The pasteurization curve has the finality to stipulate the conditions in that the mother's milk will need be submitted to be considered pasteurized. A problem found out on making the curve in Londrina-PR is the temperature oscillation. So, this research shows a method that enables the temperature control from the thawing milk to the end of pasteurization.
\end{abstract}

\section{INTRODUÇÃO}

O banco de Leite Humano de Londrina, instalado no Hospital Universitário Regional do Norte do Paraná (HURNP), órgão suplementar da Universidade Estadual de Londrina (UEL), foi inaugurado em novembro de 1988 , com a finalidade de atender crianças que necessitam de leite materno e que, por diversas razões, estejam impossibilitadas de recebê-lo de suas próprias mães.

As doadoras de leite são nutrizes sadias que apresentam secreção lática além das exigências de seu filho e que se dispõem a doar esse excesso espontaneamente.

Após coletado, o leite é submetido a um processo denominado de pasteurização, cu ja finalidade é prolongar o período de utilização e preservar suas características.

A pasteurização é um tratamento aplicado ao leite, que visa a inativaçã̃o témica de $100 \%$ das bactérias patogênicas e de $99 \%$ de sua flora saprófita. O binômio temperatura/tempo é calculado de modo a obter a inativação térmica do micro-organismo $\mathrm{Co}$ xiella brunetti (o leite é submetido a uma temperatura de $62.5^{\circ} \mathrm{C}$ por 30 minutos e em seguida sofre um resfriamento rápido em recipientes contendo água e cubos de gelo)!

Para a implantação do Banco de Leite Humano de Londrina, a equipe envolvida realizou treinamento específico no Banco de Leite Humano de referência no Paraná, situado no Hospital de Clínicas de Curitiba. Durante o curso, recebeu-se orientação quanto à técnica de elaboração de curvas de pasteurização. A confecção da curva de pasteurização é uma etapa de suma importância onde são estabelecidas as condições (tempo e temperatura) em que o leite humano deverá ser submetido para que seja pasteurizado.

Na elaboração da curva de pasteurização no Banco de Leite Humano de Londrina perceberam-se oscilações constantes de temperatura, motivo pelo qual optou-se por modificar o seu controle durante a pasteurização.

\section{OBJETIVO}

Relatar a forma de controle de temperatura do leite durante o processo de pasteurização no Banco de Leite Humano de Londrina.

- Professor Adjunto do Departamento de Enfermagem da Universidade Estadual de Londrina - PR

** Professor Assistente do Departamento de Enfermagem da Universidade Estadual de Londrina - PR 


\section{MATERIAIS E MÉTODOS}

No Banco de Leite Humano do Hospital de Clínicas de Curitiba são obedecidos os seguintes passos para a elaboração da curva de pasteurização:

- Utilizar frascos contendo leite de vaca com mesmo tamanho e volumes aproximados de leite.

- Regular a temperatura da água do banho-maria à temperatura desejada.

- Verificar a temperatura de cada frasco, mantendo um termômetro imerso em cada um.

- Verificar a temperatura dos frascos, a cada cinco minutos

- Observar o momento em que a temperatura de todos os frascos atinge $62,5^{\circ} \mathrm{C}$ e a partir daí cronometrar o tempo durante 30 minutos. A cada 5 minutos, aferir a temperatura, afim de assegurar que esta se mantenha em $62,5^{\circ} \mathrm{C}$. Portanto, as amostras permanecem a $62^{\circ}, 5 \mathrm{C}$ durante $30 \mathrm{mi}$ nutos. Para que o leite atinja a temperatura de $62,5^{\circ} \mathrm{C}$, em Curitiba, aguarda-se em torno de 10 a 15 minutos.

Segundo a orientação recebida, várias curvas de pasteurização foram realizadas em dias diferentes, na tentativa de se estabelecer as condições de trabalho para Londrina. Observou-se, com isto, variações da temperatura nas diversas curvas, ocorrendo um intervalo entre 10 a 25 minutos até atingir a temperatura de $62,5^{\circ} \mathrm{C}$. Estas oscilações de temperatura causadas porvavelmente por diferenças na espessura da parede dos frascos que contém o leite, ou até mesmo alterações ambientais, provocaram insegurança na equipe quanto à eficácia da pasteurização do leite, uma vez que não se conseguiu estabelecer exatamente quanto tempo o leite levaria para atingir $62,5^{\circ} \mathrm{C}$.

Frente às dificuldades encontradas optou-se então por modificar a técnica de controle de temperatura durante a pasteurização.

A modificação consiste em substituir a elaboração da curva de pasteurização por um frasco conten- do leite materno, que possui um termômetro acoplado à sua tampa. Este frasco, denominado de "f rasco controle"é utilizado durante todo o processo, obedecendo os seguintes passos:

1. Utilizar o "frasco controle" do mesmo tamanho, contendo o mesmo volume de leite dos frascos sem serem pasteurizados.

2. Retirar o "frasco controle" do freezer juntamente com os demais frascos a serem pasteurizados.

3. Aguardar o descongelamento total de todos os frascos a serem pasteurizados, inclusive do frasco controle.

4. Regular a temperatura da água do banho-maria à temperatura desejada.

5. Colocar todos os frascos contendo leite humano e mais o frasco controle dentro do banho-maria.

6. Observar pelo termômetro do frasco controle o momento em que a temperatura atinge $62,5^{\circ} \mathrm{C}$, e a partir daí, cronometrar o tempo durante 30 minutos. A cada 5 minutos, aferir a temperatura, afim de assegurar que esta se mantenha a $62,5^{\circ} \mathrm{C}$.

7. Colocar os frascos em recipientes com água e gelo, após permanecerem 30 minutos a $62,5^{\circ} \mathrm{C}$.

$\mathrm{O}$ aparelho utilizado como pasteurizador é um banho-maria elétrico, de marca FANEM, com agitador da água, o que permite a distribuição homogênea da temperatura. $O$ ajuste da temperatura da água e do aparelho é facilitado porque o aparelho apresenta controle digital que permite programar $o$ ajuste da temperatura da água circulante e do aparelho simultaneamente.

\section{CONCLUSÃO}

Com a utilização deste frasco controle durante todo o processo de pasteurização, obtém-se a segurança de que o leite humano está sendo submetido à temperatura de $62,5^{\circ} \mathrm{C}$ por 30 minutos, independente da presença de fatores que possam interferir na temperatura do leite alterando o processo de pasteurização.

\section{REFERÊNCIA BIBLIOGRÁFICA}

1 INSTITUTO NACIONAL DE ALIMENTAÇÃO E NUTRIÇÃO. Recomendações técnicas para funcionamento de banco de Leite Humano. Brasilia: INAN, 1987. 